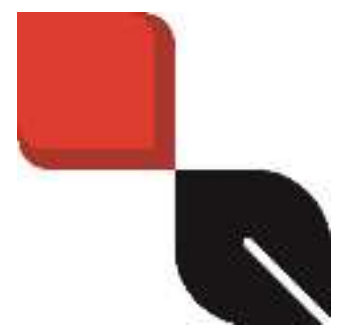

Cuadernos del CILHA n 34 - 2021 | publicación continua

ISSN 1515-6125 | EISSN 1852-9615

http://revistas.uncu.edu.ar/ojs/index.php/cilha/

CC BY-NC 2.5 AR

Recibido: 23/04/2021 Aprobado: 20/06/2021

PP. 1-34

DOI: https://doi.org/10.48162/rev.34.004

\title{
"Lo que piensa la juventud..." Inicial y su intervención conceptual
}

\author{
What youth thinks... Initial and its conceptual intervention
}

\author{
María Carla Galfione \\ Universidad Nacional de Córdoba \\ Instituto de Humanidades \\ Consejo Nacional de Investigaciones Científicas y Técnicas de Argentina \\ carlagalfione@yahoo.com.ar
}

Argentina

Resumen: Partimos del reconocimiento de la revista Inicial como parte y expresión contundente de la transformación cultural que caracteriza los años veinte en Argentina. Un cambio que puede considerarse desde diversas perspectivas, aunque todas señalan la novedad radical que traía aquella invitación a pensar desde una "nueva sensibilidad" y en un "tiempo nuevo". En ese marco, Inicial es leída aquí poniendo atención especial al despliegue filosófico que desde sus páginas permitían afirmar esa novedad. Recorremos las notas editoriales y algunos de sus artículos, advirtiendo cómo afirman y entrelazan los elementos conceptuales que permiten construir la base sobre la cual puede afirmarse el corte con el pasado. Si a simple vista puede verse una diferencia con otras expresiones culturales previas, lo que nos interesa aquí en ahondar en la construcción filosófica de esa diferencia. En especial, decimos, la novedad que se proclama sólo puede ser postulada y comprendida como tal sobre el suelo particular que supone una 
"Lo que piensa la juventud..." Inicial y su intervención conceptual

reconfiguración de la temporalidad. $Y$ desde ahí leemos también algunas de sus derivas o implicancias, tan presentes en el imaginario de la época: el rol de una intelectualidad, el estrecho vínculo que se establece entre lo que muere bajo el peso de este tiempo nuevo y algunas ideas y expresiones políticas contemporáneas, el lugar que le cabe a América Latina y su inscripción en Occidente y la exigencia que recae sobre la universidad y, con ello, sobre la Reforma Universitaria.

Palabras clave: Revista Inicial, Cambio conceptual, Tiempo nuevo, Nueva sensibilidad.

Abstract: We start from the recognition of the magazine Inicial as part and forceful expression of the cultural transformation that characterizes the twenties in Argentina. A change that can be considered from various perspectives, although all point to the radical novelty brought about by that invitation to think from a "new sensibility" and in a "new time". Within this framework, Inicial is read here paying special attention to the philosophical unfolding that from its pages allowed affirming that novelty. We go through the editorial notes and some of his articles, noticing how they affirm and intertwine the conceptual elements that allow to build the base on which the cut with the past can be affirmed. If at first sight a difference with other previous cultural expressions can be seen, what interests us here is to delve into the philosophical construction of that difference. In particular, we say, the novelty that is proclaimed can only be postulated and understood as such on the particular ground that implies a reconfiguration of temporality. And from there we also read some of its derivations or implications, so present in the imaginary of the time: the role of an intelligentsia, the close link established between what dies under the weight of this new time and some contemporary political ideas and expressions, the place that belongs to Latin America and its registration in the West and the demand that falls on the university and, with it, on the University Reform.

Kewords: Inicial review, Conceptual change, New time, New sensibility.

La mayoría de los relatos y periodizaciones de cultura y la filosofía en Argentina reconocen en torno a 1920 un momento de inflexión o de cambio en el que comenzaría a cerrarse un proceso de desplazamiento del positivismo. La periodización que ofrece Diego Pró y que ha adquirido un valor indiscutido, señala el inicio de ese tránsito allá por 1910, fecha muy significativa para la cultura argentina, y se anima a reconocer la última etapa de este desarrollo hacia mediados de la década del 20, de la mano de la

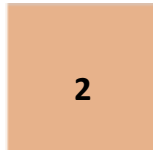

Cuadernos del CILHA n 34 - 2021

ISSN 1515-6125 | EISSN 1852-9615

CC BY-NC 2.5 AR

http://revistas.uncu.edu.ar/ojs/index.php/cilha/ 
llamada "generación del 25"1. Más allá de los límites que pueda presentar esta periodización, lo cierto es que esa idea se torna en general la base sobre la cual se lee la década y sus cambios. Se suele mirar incluso ese cambio como expresión de una sucesión cuasi natural de maduración. Esa maduración aparece como momento consecutivo a una primera germinación que manifiesta los incipientes brotes de esto que iba a ser años después. Esa idea se combina con el uso frecuente de la categoría de "generación" que impone un prisma de lectura particular, pero escasamente tematizado. En efecto, si hay algo que caracteriza a esta generación del 25 en los diversos relatos, es el reconocerse en las antípodas de las expresiones previas, el carácter "anti" que suele adjudicarse a sí misma. Pero parecen restar varias aristas aún por revisar.

En esa línea, explicado de esta u otra manera, hay consenso entre los historiadores e historiadoras acerca del hecho de que en los veinte estamos ante "una nueva conciencia filosófica", también cultural en términos más generales ${ }^{2}$. La revista Inicial. Revista de la nueva generación es una de las expresiones que protagonizan esa renovación. Si se la ha señalado y estudiado como figura central en lo que hace a la renovación estética, tanto en relación al campo de la literatura como a las artes plásticas, es cierto que no ha tenido la misma suerte su faceta filosófica ${ }^{3}$. Más allá de la tan recordada lectura que hizo Dotti, que le asignaba, aunque "con suma prudencia", el lugar del "primer vanguardismo filosófico", ${ }^{4}$ las referencias al rol que jugó la revista en el escenario de las definiciones filosóficas son muy escasas. Las razones de ese descuido pueden ser de diverso orden, debemos todavía explorarlas, pero ese no es el

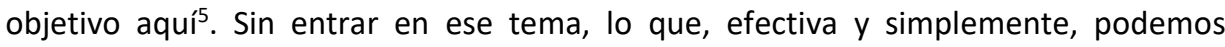

\footnotetext{
${ }^{1}$ Pró, D. (1965).

${ }^{2}$ Cfr. Peñafort, E. (1987).

${ }^{3}$ En este sentido se expresa también Velarde Cañazares, M. (2013).

${ }^{4}$ Cfr. Dotti, J. (1992).

${ }^{5}$ Velarde Cañazares, avanzando sobre este vacío de estudios, sugiere algunas explicaciones al inscribir la historia de nuestra filosofía en el panorama de las disputas ideológicas que atraviesan la historiografía argentina. Preferimos no avanzar en esta dirección y nos limitamos a sugerir que probablemente esto tenga alguna relación con la trayectoria de los autores de la revista. No se trató, salvo algunas excepciones, de docentes de la carrera de Filosofía de la UBA. Aunque ellos pueden haber ejercido en carreras de la misma especificidad en universidades del resto del país, las historias de la filosofía de que disponemos se concentran en los desarrollos de la UBA. De todas maneras, aclaramos que el objetivo de lo que sigue es más de tipo
} 
afirmar, siendo una de las principales causas de que hagamos de la revista nuestro objeto, es que Inicial reúne muchos trabajos que sirven de suelo a una reconfiguración conceptual que debe ser leída en el marco, o como expresión, de una transformación filosófica. De la mano de la reproducción de obras, planteos de orden estético en su mayoría y algunos toques de referencia a la realidad política, pareciera que una medida importante de la unidad de la publicación, aquello que la vuelve un "actor colectivo", 6 se logra a través del despliegue de algunos pocos hilos que constituyen el soporte conceptual de la renovación que se proponen sus impulsores. Reconocer esos hilos es condición para referirnos a la renovación de la que participó, no tanto porque hayamos de constatar las diferencias con lo anterior, sino más bien, en la lectura que elegimos ensayar aquí, porque puede advertirse en sus páginas la construcción misma de la diferencia, así como sus supuestos e implicancias. De alguna manera, adentrarnos en esta dimensión conceptual permite reconocer algunos elementos teóricos que desempeñaron una función fundamental en la elaboración de la renovación, explorar la génesis de aquello que se leyó como renovación, sin suponer de antemano lo que esta movida quería instalar como tal ${ }^{7}$.

Inicial es presentada por Fernando Rodríguez, de la mano de Martín Fierro, Proa, Noticias literarias, Valoraciones y Sagitario, como una de las revistas culturales que, en estrecho vínculo con el movimiento universitario iniciado en el 18, protagonizaron la renovación estético-literaria. Del mismo modo la considera Natalia Bustelo aunque

conceptual y en ese sentido recuperamos y damos prioridad a los desarrollos teóricos o filosóficos, atendiendo tanto a las remisiones de la revista a elementos filosóficos, cuando al lugar que ésta busca darle a la disciplina en el marco de la lógica que propone. No obstante no pretendemos con esto proponer una lectura del desarrollo de la filosofía como disciplina en el país, algo que implicaría al menos la inscripción de la revista y sus desarrollos teóricos en un escenario más amplio.

${ }^{6}$ Cfr. Tarcus, H. (2020).

${ }^{7}$ Avanzamos aquí sobre la base de las novedosas investigaciones en torno a las revistas culturales, que aportan elementos imprescindibles para reconocerlas en el marco de la trama cultural en que se desarrollan. En este sentido, creemos que podemos volver a recorrer elementos sustantivos de los modos como se autoidentifican las revistas, que si bien fueron desplazados por algunos "vicios" de la historia de las ideas señalados a menudo por la historia intelectual, resultan valorables. No sólo nos interesa ensayar aquí una lectura complementaria y fácilmente articulable con aquellas novedades, sino la posibilidad de reconocer aportes importantes para pensar qué hacían las publicaciones en ese escenario en que se desplegaban, cómo jugaban el rol de productoras de nuevos sentidos, algo que probablemente no pueda ser considerado sin tomar en cuenta algunas de sus condiciones formales o materiales.

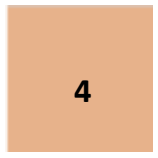

Cuadernos del CILHA n $34-2021$

ISSN 1515-6125 | EISSN 1852-9615

CC BY-NC 2.5 AR

http://revistas.uncu.edu.ar/ojs/index.php/cilha/ 
avanzando un paso más en relación con nuestro objeto. Ella la presenta como una "nueva expresión" que, sucesora de la experiencia del Colegio Novecentista y sus Cuadernos, ensaya, incluso profundiza, la exploración del vínculo entre filosofía y literatura como una nueva opción frente al caduco positivismo ${ }^{8}$. Lo que nos interesa por nuestra parte, y en ese marco, es indagar de qué herramientas conceptuales se valió Inicial para construir el andamiaje que le permitía erigirse en voz nueva de algo nuevo.

Velarde Cañazares pone en el centro de la escena la noción, deudora de la lectura de Dotti, de "vanguardia filosófica" para referirse a algunos de los autores de la revista. No partimos de allí y preferimos hablar de renovación, aunque incluso este término requiera algunas precisiones y cuidados. Hablar de "vanguardia" supone, tanto aclarar los criterios que permitirían incluir o excluir las diversas expresiones en ese grupo, cuanto, y sobre todo, una serie de supuestos historiográficos con los que no queremos comprometernos $^{9}$. La revista, desde su nombre mismo, se presenta como novedad histórica. Nos interesa revisar el sentido de ese relato que crea de sí, en qué diagnóstico se apoya, qué rol se da a sí misma para hacer efectiva esa renovación y cuál es su alcance.

Lo referido a esa renovación, por último, toca de cerca a la filosofía como saber. Ésta recibe directamente sus ecos, en parte, porque en aquella búsqueda se toman las herramientas que la filosofía despliega principalmente en sus desarrollos europeos; en parte, porque los cambios que proponía en el marco de la cultura argentina, suponen,

\footnotetext{
${ }^{8}$ Cfr. Bustelo, N. (2010).

${ }^{9}$ Es cierto que en la revista aparece ese término en algunas oportunidades y podría traerse aquí en el mismo sentido en que se usa ahí. Sin embargo, cada vez que se utiliza allí es para señalar aspectos propios de las novedades artísticas, con lo cual el uso que nosotros hiciéramos requeriría una adaptación. Por otra parte, según la teoría estética, pueden ser varios los sentidos en que se utiliza "vanguardia", pero en general es un modo de pensar la relación de lo nuevo con lo viejo, aunque también con lo nuevo que aún no es. Valorar nuestro objeto de esa manera supone una determinada concepción acerca del modo cómo las ideas o la filosofía se despliegan en la historia. Esa concepción es, necesariamente de quienes contamos esa historia, y en ese sentido cuesta tomar como propias, para contar una historia, su devenir, sus cambios y continuidades, las expresiones de los mismos autores. Por más novedad que quieran ver los protagonistas, como lectores, creemos, no estamos obligados a verla también, deberíamos conformarnos con pensar por qué y cómo podían afirmar esa novedad. Para analizar en particular la cuestión de la vanguardia literaria ver: Rodríguez, F. D. (2004).
} 
"Lo que piensa la juventud..." Inicial y su intervención conceptual

tal como veremos, otorgarle un papel especial y con contornos definidos a esta disciplina.

\section{Un nuevo tiempo. Redefiniciones conceptuales}

En ese marco, en lo que sigue partimos del reconocimiento y la presentación general de la revista que ofrece Fernando Rodríguez en la edición fascimilar, evitando entonces detenernos en elementos de tipo material y formal ${ }^{10}$. Nos interesa atender con más precisión al discurso filosófico que se proclama desde sus páginas y que, según nuestra lectura, es lo que permite elaborar la base a partir de la cual la revista se da identidad como hacedora de una nueva época, como protagonista y responsable de llevar adelante la tarea que le cabe a su presente. De esa manera, podemos ya distinguir un primer objeto de análisis: el modo cómo presenta su tiempo, las particularidades de ese presente y la forma en que éste se percibe, inscripto en un escenario mayor que podríamos denominar, aunque con cuidado, la historia. Es ese, según nuestra lectura, el piso sobre el que resulta medianamente posible, y sobre todo coherente, luego, señalar la tarea y el perfil de la filosofía que propone.

\footnotetext{
${ }^{10}$ Anotemos, rápidamente, que Inicial se publica en Buenos Aires, entre octubre de 1923 y mayo de 1927, con un total de 9 números que salen a la luz con cierta irregularidad. Tal como detalla el número 8 , el equipo editorial estaba compuesto de la siguiente forma: “Director: Homero M. Guglielmini; redactores: Roberto A. Ortelli, Roberto Smith, V. Ruiz de Galarreta, Miguel Angel Virasoro, Hector H. Irusta, Armando Levene, Manuel Juan Cruz, Vicente Fatone, Horacio Ferreyra Díaz, Ricardo F. Molinari, Carlos M. Onetti". (634). Sin embargo, no siempre fue así. En 1923 los redactores eran Ortelli, Brandan Caraffa, Smith y Gugliemini, y el administrador era Ruiz de Galarreta. Ese equipo se mantiene hasta abril del 24 cuando el grupo se quiebra, en palabras de Brandán Caraffa, por "divergencias ideológicas y sentimentales" (Inicial, 2004, 281). El grupo disidente, encabezado por Brandán Caraffa, edita un número más, el número 5. El otro grupo, que mantiene aquellos nombres, reemplazando el de Brandán por el de Ruiz de Galarreta, también edita un número 5 y se mantiene estable hasta el 11. Cabe destacar que en las páginas de la revista participan otros nombres, pero en general los artículos de los colaboradores son sólo esporádicos y, en algunos casos, cuesta articularlos teórica e ideológicamente con los de la línea editorial. A los fines de este análisis nos hemos ceñido a la revista "oficial", aquella que continúa hasta el 27, y hemos tomado en la medida de lo posible los artículos que reflejan su línea rectora. Nos interesa presentar la revista y no los casos aislados. En el mismo sentido, es probable que esta lectura pueda completarse con el análisis de las trayectorias y desarrollos teóricos particulares de quienes formaron parte de este proyecto, pero en esta oportunidad nos queremos concentrar en la revista, confiando en que este agrupamiento y proyecto editorial dice más de la época que los casos aislados.
}

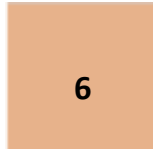

Cuadernos del CILHA n $34-2021$

ISSN 1515-6125 | EISSN 1852-9615

CC BY-NC 2.5 AR

http://revistas.uncu.edu.ar/ojs/index.php/cilha/ 
De estas definiciones podrán extraerse algunas aclaraciones en relación con otros temas que a menudo se abordan de la revista, motivos muy propios de los veinte: su lectura y voluntad de intervención en el proceso de la Reforma Universitaria, su valoración de América o defensa del americanismo, su mirada de la Revolución Rusa, por nombrar algunos. Aunque ese no sea nuestro objetivo central, creemos que el señalamiento de los vínculos de las definiciones filosóficas con esos motivos más bien históricos sugiere un diálogo que puede dar claridad en ambas direcciones.

Una primera mirada de las preocupaciones y tomas de posición de la revista puede hacerse a través de un repaso de sus notas editoriales. Éstas en general no llevan firma, lo que permite suponer la autoría de todo el grupo editor, que en cada número se especifica como "redactores" en la portada. Allí nos encontramos con algunos elementos constantes que, principalmente, hablan del valor de novedad que se otorga la publicación y la intervención que ello supone en la cultura argentina y latinoamericana de la época: es tribuna libre para la juventud, que encontrará allí un medio para alzar su voz, y es medio de combate despiadado contra expresiones morales y artísticas del medio ${ }^{11}$. Al interior, estas formulaciones suponen algunos elementos más: esa juventud, que es explícitamente señalada como "juventud argentina", contiene "un germen de plenitud y perfección" que la revista viene a salvar al contribuir con su desarrollo. Se apoya en valores como la vida, el amor, la verdad, "todo lo que es bueno y todo lo que es bello", resume. $Y$ en función de esas creencias se afirma la importancia de renovar las expectativas. La esperanza crece ante el postulado de un futuro en que germinará aquella semilla y en que vendrán los héroes. Se levanta como voz de combate, que incluso llega a reconocer el costado positivo de la guerra que acaba de terminar: "ha sido fructífera; ha removido, como un torbellino, todas las inquietudes que dormitaban, latentes, en el fondo de la conciencia universal" 12 . Reivindica la lucha siempre y cuando sea por esos ideales y sea encarnada por esa juventud que marca una diferencia: es "valiente", "decidida" y "sana". Una juventud iconoclasta, que tira abajo los viejos ídolos. De todos los "contra" que se proclaman en

11 “¿Queréis saber cómo piensa la juventud argentina? Leed INICIAL, Revista de la nueva generación”, rezaban algunos carteles en las calles de Buenos Aires, anunciado la pronta salida de la revista, según cuenta Fernando Rodríguez (Rodriguez, 2004, p. 7).

${ }^{12}$ Inicial (2004), p. 49. 
esa primera editorial, el que más destacamos en función de nuestro objetivo es el que se dirige a los maestros, a los que se erigen en "maestros de la juventud" y, en relación con la filosofía, esto toma una forma precisa: "contra los diletantes que hablan a la juventud sobre filosofía y ciencia repitiendo todos los días la simulación de lo que no se sabe $^{\prime 13}$. No hace falta mucha suspicacia para advertir que ese modelo tiene nombre: José Ingenieros.

Esta tensión es estructural y vuelve a aparecer insistentemente en las diferentes editoriales de la revista: siempre se levanta una bandera, pero en el marco de una contienda explícita. Se articula ahí su interés de ser vocera de algo que la excede al tiempo que impugnadora de aquello que la novedad viene a reemplazar. Y allí es donde Inicial encuentra su justificación más ajustada: viene a ser la voz y la acción de lo que la época establece como condición y exigencia. En ese sentido, las editoriales son expresión también de los debates del momento, de las diferencias con otras líneas intelectuales y políticas y de la toma de posición ante ciertos acontecimientos. En efecto, está atenta a definir las cuestiones de la hora presente y a tomar una posición. Así, en el número 2, respondiendo a algunas críticas, se señala la caducidad de ciertas ideas, el marxismo en particular, "la teología marxista", que no reconoce las nuevas verdades. "Hoy todo ha cambiado", dice esa editorial, y es imperioso atender a esos cambios. Pero no son transformaciones ideológicas o políticas, según se presentan. Se trata, ante todo, de un nuevo tiempo.

En ese sentido se expresa el número 4 en el que la novedad queda definida: es el fin de los sistemas, el fin de la ciencia como valor absoluto, el fin de las revoluciones. Resabios de los siglos pasados, que caen junto con sus ideales para dejar lugar a las "cosas vivas" y a la sensibilidad que puede percibirlas. Y aquí, además de señalar tres nombres que inspiran la revista: Spengler, Ortega y Gasset y Bersgon, los que sólo falta agregarle, aunque nunca con el mismo protagonismo, los de Croce y Sorel, se vale de sus aportes para señalar el rumbo que ha tomado, o debe tomar, la civilización occidental. ${ }^{14}$ Contra

13 Inicial (2004), p. 49.

${ }^{14}$ Oscar Terán afirma que en Inicial puede reconocerse "una fuerte y explícita influencia soreliana" (Terán, 2008). Según nuestra lectura, sin embargo, Sorel no resulta una de las figuras centrales. Aunque, por cierto, es explícitamente mencionado: lo encontramos en el primer número en rotundo contrapunto con el

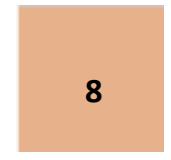

Cuadernos del CILHA n $34-2021$

ISSN 1515-6125 | EISSN 1852-9615

CC BY-NC 2.5 AR

http://revistas.uncu.edu.ar/ojs/index.php/cilha/ 
algunas críticas recibidas, se advierte que la valoración de la vida no supone el regreso al modelo apolíneo y pagano de los griegos. Si reivindicar la "vida", dicen, puede parecer pagano, seamos paganos pero a condición de reconocer esa diferencia que ofrece el actual carácter faústico: una vida que se despliega infinitamente y con conciencia. Y el modelo, se agrega, yace en nuestra propia raza: en la "silueta absurda de Don Quijote, afirmación de la idealidad y del alma (...) en un impulso libérrimo y gótico hacia el espacio infinito" ${ }^{15}$.

La presentación de esa novedad en términos de autoridades filosóficas va acompañada de una revisión de las antiguas. En particular, el número 5 se ocupa de Kant, aunque, indirectamente. El motivo de esa referencia, más que el filósofo alemán, lo constituyen sus lectores argentinos, aunque no se dan detalles al respecto. Allí, la filosofía de Kant termina por confundirse con el neokantismo: "una racha de neokantismo febril ha pasado por todos los espíritus con motivo de las recientes fiestas universitarias de que fuera objeto la memoria del gran filósofo", ${ }^{16}$ comienza diciendo esa editorial. A pesar de la ironía de esa lectura, reconoce en Kant un aporte: permitió elaborar la crítica al pensamiento dogmático y sobre esa base pudo erigirse el pensamiento contemporáneo. Pero con ello desplazó la posibilidad de pensar en términos metafísicos y eso es lo que busca recobrar la línea que sigue la revista. Si Kant confinó el noúmeno más allá del tiempo, de lo que se trata ahora, bajo la impronta del intuicionismo, es de traerlo de nuevo, pero ahora sí instalándolo en la historia.

Siguiendo de cerca las editoriales, no podemos menos que notar que la del número 9 lleva por título "Ingenieros", y resulta un condensado de aquello que Inicial está en vías de superar, recordando la editorial del primer número. Ante la muerte de Ingenieros,

marxismo, herramienta para combatir la lógica economicista (Terán, 2008, pp. 74-75). Del mismo modo vuelve a aparecer en el número dos, en que regresa sobre aquel desarrollo para enfatizar algunos elementos (Terán, 2008, p. 107). Junto con Sorel, lo destaca también Terán, encontramos la figura de Nietzsche, sobre todo revisitada en los textos más encendidos. Si bien hay diferentes elementos que hacen pensar en una inspiración general del filósofo alemán sobre la línea central de la revista, éstos son más generales y cumplen el rol de diagnosticar el final de la lógica vigente hasta entonces, sin ser, como ocurre con los otros autores, un interlocutor del momento, junto con el cual se busca dirimir y precisar los elementos fundantes de la novedad.

${ }^{15}$ Inicial (2004), p. 226.

${ }^{16}$ Inicial (2004), p. 355. 
distanciándose de las miradas elogiosas aunque reconociendo el importante rol que aquél habría cumplido en su momento, se afirma la necesidad de revisar su trayectoria "enclavándolo dentro del área del pensamiento contemporáneo". Aclara inmediatamente: "contemporáneo [...] en su profunda acepción: pensamiento vivido, pensamiento que se siente actualizado por íntima urgencia espiritual de los nuevos hombres". ${ }^{17}$ Desde este punto de vista, Ingenieros presenta "una más comprensiva síntesis de todo lo que debe ser superado, de todo lo que debe ser perentoriamente desplazado". Y allí se condensa lo que la revista declara caduco en términos de saberes o lógicas: psicologismo, darwinismo, naturalismo, determinismo y comunismo.

Es interesante esta nota necrológica porque, habiendo avanzado bastante en los números de la revista, Inicial parece todavía reconocer la necesidad de insistir sobre su descripción de lo que no debe ser considerado más que negativamente para el despliegue esperado o natural del momento que se vive: "aceptar la ideología de Ingenieros importa incorporarla como lastre inactual y entorpecedor al proceso de nuestra cultura; y es sólo negándola que ella se vuelve fecunda"18. Así la revista se presenta como una vuelta de página, y la muerte de Ingenieros casi se presenta como la constatación de esta novedad. De cara a lo que muere se invoca el "fervoroso sentimiento de la vida".

En el número 10 se completa o ajusta esta idea, poniendo a la universidad en el centro de la escena. Con la firma de Guglielmini, esa editorial revisa el sentido de la reforma y disputa contra la función social que algunos quieren otorgarle. Pero vemos que el debate ancla, en última instancia, en un determinado modelo de pensamiento y filosofía sobre el que debe establecerse el proyecto. Contra ella, la tarea de la universidad se concentra en la "reforma integral de la inteligencia y de la cultura" 19 . Nuevamente encontramos aquí el señalamiento de un rasgo que se impone al presente: la reforma debe concentrarse en la sustitución de los estudios, abandonar la orientación "materialista y positivista" para optar por la "humanista y filosófica". "La nueva era universitaria argentina se caracteriza por la reafirmación enérgica de los

17 Inicial (2004), p. 637.

${ }^{18}$ Inicial (2004), p. 639.

${ }^{19}$ Inicial (2004), p. 695. 
valores espirituales, en el sentido de su absoluta autonomía frente a la ciencia natural, tal como predica la filosofía contemporánea" ${ }^{20}$. Lo que sea esa filosofía contemporánea excede a las expresiones locales y se vislumbra en otro nivel por el que se le reconoce el valor de deber ser, de modelo a seguir. Lo mismo pasa con las funciones que se le otorga a la universidad: el cambio de eje depende de lo que la universidad deba ser en este nuevo tiempo. Con lo cual se suma aquí otro elemento que aparece a veces más, a veces menos explícito: hay quienes pueden señalar ese deber ser, son jóvenes que no esperan la llegada de la buena nueva, sino que ya cuentan con ella.

Reconocer ese tiempo es condición para luego avanzar en su despliegue. $Y$ en ese sentido se presenta el texto que abre el número 3 , en el que encontramos una defensa de la guerra como medio de progreso, algo que estaba sugerido también en el primer número. La guerra se comprende en este sentido, por momentos se justifica $y$, de la mano de Renán, es la opción a adoptar. Hay principios y condiciones que la hacen deseable. Pero éstos no se dan entre las naciones sudamericanas y mostrar esto es el objetivo de esa nota. Frente a un posible enfrentamiento con Brasil, se defiende allí la hermandad de estas naciones, y se recuerda que la verdadera amenaza la constituyen los Estados Unidos: "Estados Unidos es el enemigo común de América Latina. Contra ese peligro debemos armarnos" ${ }^{\prime 2}$.

El tema vuelve a aparecer algunos números más adelante, más precisamente en el número 8 , bajo el título "Iberoamericanismo". Allí, con motivo de la convocatoria al Congreso de la Juventud Latinoamericana y de ciertas diferencias presentadas en ese marco, la "América Íbera", como le llaman ahí, es ubicada en las antípodas de los Estados Unidos ${ }^{22}$. Aquella América posee caracteres privativos que se invocan como constitutivos y que permitirían sostener la resistencia frente proyectos de transformación social, política o económica. Esa América de raíces latinas, se da la mano con la espiritualidad para distanciarse de definiciones materialistas, marxistas y/o positivistas. Y así pueden reclamar, haciendo pié en una determinada definición cultural de la región y contra otros grupos, que: "la verdadera batalla se libra en el terreno

\footnotetext{
${ }^{20}$ Inicial (2004), p. 698.

${ }^{21}$ Inicial (2004), p. 166.

22 Inicial (2004), p. 565.
} 
cultural”23. Este terreno, lo venimos viendo, aún en construcción, se define por su total autonomía respecto de las otras dimensiones. Establecer esta condición resulta fundamental para que la revista determine sus propias bases de acción, pero nunca se presenta como una arbitrariedad: las condiciones que impone el tiempo y el lugar son el piso que lo hace posible.

El señalamiento de ciertos rasgos culturales propios o identitarios se hace más explícito en el número 7. Se buscan los rasgos argentinos, se pretende hablar de "argentinismo" y para ello se establece la polaridad con Europa, no tanto con los Estados Unidos, aunque esa diferencia parece ya supuesta. Contra el europeísmo de la cultura, la publicación atrae la mirada hacia la "barbarie", advirtiendo la centralidad del sentido nietzscheano del término: es potencia que debe ser irrigada en las venas de Europa. Toca a la cultura y al arte autóctono protagonizar este movimiento. Si lo nuevo, lo propio del siglo reclama atención a la cultura, la revista parece no querer descuidar cierta coherencia conceptual y señala ciertos rasgos sobresalientes de la cultura argentina para hacer pié24.

Parece sugerido ya en sus referencias a la guerra o a los conflictos en América Latina, que la revista se maneja en un amplio terreno de reflexión. De la preocupación filosófica puede pasar a la política. Y esto es lo que pasa en "La democracia en crisis", la nota que abre el número 6. Según lo que se afirma allí, la democracia también es algo superado, caduco. Un sistema político estructurado al servicio de intereses de otro tiempo y, por ello, es de suponer, con principios de otra época. Un legado del siglo pasado, que el siglo XX, en las expresiones del fascismo y del comunismo, se anima a discutir ${ }^{25}$.

El repaso que hicimos presenta con más o menos detalle el perfil general de la revista. $Y$ con más o menos detenimiento al interior de sus números se aborda uno u otro tema.

\footnotetext{
${ }^{23}$ Inicial (2004), p. 567.

${ }^{24}$ Sobre todo en los primeros números, esta posición se da la mano con la invocación de la figura de Ricardo Rojas como autoridad. No obstante, y probablemente a diferencia de aquél, no se destacan rasgos precisos o particulares de esta cultura. En última instancia, como veremos más adelante, parece tratarse de una intuición que permite reconocer en Argentina, o en América, una condición especial, sin que parezca necesario demostrarlo con detalle.
}

25 Inicial (2004), p. 414.

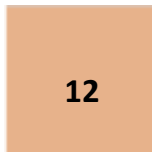

Cuadernos del CILHA n 34 - 2021

ISSN 1515-6125 | EISSN 1852-9615

CC BY-NC 2.5 AR

http://revistas.uncu.edu.ar/ojs/index.php/cilha/ 
La tónica general, como hemos visto, es la de la renovación, es la del señalamiento de una cambio, una novedad que comienza y a la que Inicial le daría lugar precisamente encarnándola. En esas notas vemos cómo se sostiene una tensión, positiva, podríamos decir, entre lo que debe ser y lo que debe hacerse para acompañar ese deber ser. No obstante, el deber ser no es algo lejano, no es un deseo o dictum por realizar, sino que ya se estaría desplegando. La novedad se afirma como característica del tiempo en que se vive, suponiendo entonces una ruptura de hecho con lo anterior. Aunque más que como ruptura se presenta como señalamiento de su caducidad natural, ante la cual, Inicial toma la posta que le corresponde tomar. Estamos, sin duda, ante la elaboración de una imagen de la historia y de sus momentos. Aquella como sucesión sin solución de continuidad. Hay miradas concesivas al pasado, escasas eso sí, pero cuando éstas aparecen ese pasado no es inmediato. Se insiste en el corte, en la interrupción respecto de lo inmediato y en la inauguración de una novedad que, si conserva algo del pasado, lo es de un pasado más bien remoto y más bien difuso en términos cronológicos. Hay, decimos, una construcción sistemática de la temporalidad sobre la que la revista elabora su razón de ser: un tiempo no único o unificado, una historia en movimiento constante que reclama ser reconocido como el "sentido histórico de los fenómenos humanos", ${ }^{26}$ transformando allí el sentido de "lo histórico". Se insiste en el señalamiento del "hoy", de los cambios que trae ese presente, variaciones que sobre todo se reconocen, precisamente, en los sentidos de los viejos conceptos o lógicas, entre los que la de la historia ocupa un lugar central.

Así, esa falta de continuidad que se anuncia se articula con la imposibilidad de previsión, con la falta incluso de conocimiento sobre la historia. Aquella centralidad del hoy, esa historia en permanente y radical renovación se da la mano con la afirmación de la historia como movimiento "inconciente", en el sentido de no dependiente de una razón que la ordena, aunque no por ello como tendencia caótico. Herramienta que permite conjurar tanto cualquier tipo de ciencia de la historia, confiada en sus capacidades predictivas, cuanto cualquier movimiento de intervención planificada sobre el desarrollo histórico. "La historia se convierte en la epopeya heroica de la personalidad humana que a través de los siglos crea y modifica las normas a las cuales adecua su

${ }^{26}$ Inicial (2004), p. 104. 
acción"27. En un gesto casi fatalista, lo que queda es reconocer la necesidad de cada momento histórico, que se impone por su propia fuerza, y ensayar algún sentido que permita acomodarse a él. Disponerse a seguirle el juego a la historia y su devenir. Asistir al momento histórico, dicen invocando a Ortega y quizás valiéndose de la doble significación de la palabra. Asistir a un momento que está caracterizado por la crisis. Ser parte de él, participar, y con ello contribuir heroicamente a su despliegue. Y eso es, precisamente, lo que se propone hacer la revista una vez que ha logrado definir ese modo de proceder de la historia: intervenir, producir, fomentar, discutir para abrirle camino a las nuevas formas de un tiempo nuevo contra la persistencia de un modelo caduco.

Inicial toma como propia, sobre aquel escenario, la tarea de construcción de lo nuevo. El deber ser puede cobrar visos de urgencia e imprescindibilidad porque esa atmósfera de cambio profundo descripta, así lo requiere ${ }^{28}$.

\section{Filosofía de ese tiempo}

Sobre esa base, entonces, que atraviesa todos los planteos y se recuerda permanentemente, puede ensayarse una organización general que distingue tres cuestiones que, en íntima y explícita relación, señalan las principales preocupaciones del grupo que conduce la revista: por una parte, la tematización de la transformación teórica o conceptual, la determinación de los conceptos y las bases teóricas sobre las cuales busca asentarse la revista. En ese marco debemos considerar la mención de los referentes, del mismo modo que el señalamiento de sus diferencias con autores de la época. En segundo lugar, lo referido a la mirada especial que reclama la cultura

\footnotetext{
27 Inicial (2004), p. 699.

${ }^{28}$ No hay referencias explícitas a Bergson en estos desarrollos, pero es muy claro que sus ideas recorren toda la revista. No nos interesa una indagación en términos de recepción, pero es importante notar esa fuerte impronta bergsoniana y que se hace muy evidente en relación con el tema del tiempo-historia que venimos mencionando. Quizás pueda pensarse que puedan ser razones externas, en particular políticas, las que sugieren evitar la recurrente mención del francés. En general es claro que en la revista se exalta la cultura española, italiana y, en menor medida y de manera condescendiente, la alemana, pero Francia es duramente condenada. Se toma partido en relación con las posiciones adoptadas en diversos sucesos en torno a la guerra y se condena, por ejemplo, "la hipocresía literaria de Francia que esconde su vanidad imperialista bajo el aluvión de sus academias y de sus príncipes literarios de exportación" (Inicial, 2004, p. 71).
}

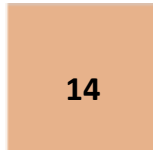

Cuadernos del CILHA n 34 - 2021

ISSN 1515-6125 | EISSN 1852-9615

CC BY-NC 2.5 AR

http://revistas.uncu.edu.ar/ojs/index.php/cilha/ 
hispanoamericana en sus diversas manifestaciones. Y por último, las reflexiones en torno a la actualidad política, algunos señalamientos, denuncias y tomas de distancia.

Para lo que nos interesa aquí, no cabe duda de que el primer punto es el de mayor centralidad, pero vale la pena estar atentos a estos otros que lo rodean y colaboran en su comprensión. En parte, hemos avanzado con la cuestión teórica al referirnos al sentido del tiempo y la historia. En la mayoría de los artículos de corte más filosófico hay un lugar reservado para alguna referencia al tiempo. Probablemente, porque sea ese supuesto, como dijimos arriba, la condición de posibilidad de la revisión de la antigua lógica, entendiendo que sólo puede haber algo nuevo, radicalmente nuevo, si antes se habilita conceptualmente esa posibilidad. El abandono del modelo de la razón moderna, que puede verse tanto en la crítica a Kant y al positivismo, cuanto en la valoración de Bergson, Ortega y otros, obliga a pensar no sólo el tiempo y sus desplazamientos de otro modo, sino también el conocimiento, los valores y hasta la política, por nombrar algunos de los grandes temas de que suele ocuparse la filosofía.

Esa renovación reclama que la mirada se pose no ya en procesos mentales o abstractos, y mucho menos en procesos cognitivos o intelectivos, sino en la vida. La atención a la vida es ahora la exigencia de la filosofía en la medida en que la vida ocupa el centro de esta época. Así, el positivismo, ajeno a la vida, es presentado en oposición a la filosofía, como "la negación de sus valores fundamentales" 29 . Nuevamente, un supuesto que no se define ni se tematiza, pero que se instala como condición de lo posible. La vida se presenta como lo opuesto al intelecto $y$, en ese sentido, la filosofía no despliega sistemas de pensamiento, razonamientos lógicos consistentes y argumentos con pretensiones de generalidad, sino que encarna más bien la voz de esas expresiones cambiantes de una voluntad de vivir. El vitalismo nietzscheano atraviesa todo el planteo, poniendo al filósofo alemán como garante último de las afirmaciones que se ensayan, la crítica al racionalismo y la posibilidad de afirmar, más allá de éste, el valor de lo irracional. El impulso vital señala en última instancia la necesidad de detener la mirada del filósofo en ciertos rasgos siempre en movimiento, causa del movimiento, previos o independientes al proceso de conocimiento que aporta el intelecto. Así, la

${ }^{29}$ Inicial (2004), p. 661. 
vida es potencia inmanente, posibilidad constante de cambio, de transformación, fuerza siempre en movimiento sin eje, y que sólo encuentra su manifestación objetiva a través de la cultura.

Los autores de la revista reclaman insistentemente esa centralidad de la cultura en la que reconocen un motivo de época que sirve para desplazar el modelo de conocimiento y de filosofía próximo a las ciencias naturales. Pero no se conforman con distinguir los saberes, se trata, en cambio, de darle centralidad a estos nuevos conocimientos que están llamados a protagonizar la época y hacer la historia. En parte, este llamado se explica por el tipo de conocimiento al que se apela. Lo que se conoce no es palpable, medible, cuantificable, no puede ser alcanzado con las herramientas del intelecto, que conduce, a juicio de estos autores, a un conocimiento único y simplificado. El conocimiento de la vida es de tipo intuitivo.

La intuición, dicen en la tan valiosa como polémica editorial del número 4, "abre la entraña de las cosas", y edifica "un simbolismo extraño y conturbador (...) que se impone a nuestro espíritu con todo el prestigio de la lógica más estricta" ${ }^{30}$. La intuición deja al descubierto el secreto de las cosas. Una capacidad humana que permite ensayar otra aproximación a lo que lo rodea. El único método del que puede valerse la filosofía si pretende conocer alguna verdad.

Se invoca insistentemente la noción de "nueva sensibilidad", una expresión muy usual en los textos de referencia de la época, algo que se lee a menudo como el signo de este tiempo. Esa nueva sensibilidad responde a este esquema: a una nueva definición de lo que es y a un nuevo modo de aproximarse a ese objeto cambiante, inmanente y espiritual. Virasoro, parte del equipo editorial, es uno de los autores que más se extiende sobre estos asuntos. En el número 8 se incluye un trabajo suyo que lleva por título "Introducción a la nueva sensibilidad", en donde se detallan algunos elementos relativos a las condiciones o supuestos que hacen posible señalar esta novedad: el objeto de la filosofía, a diferencia de lo que ocurría con la filosofía clásica, según dice, es ahora la "vida cósmica" en la que se reúnen el yo y el mundo que lo circunda. No

${ }^{30}$ Inicial (2004), p. 225. 
existe la diferencia entre sujeto y objeto, lo que hay, en tanto objeto de conocimiento o reflexión, aunque más propiamente sería de intuición, es un conjunto de "vibraciones cósmicas", en cuya percepción se reconoce el sujeto mismo. Las vibraciones se manifiestan exclusivamente en el sujeto, cuya atención se pone a prueba. El conocimiento depende de esa reacción y llega entonces a producir "símbolos de realidad". Llegan a través de una intuición particular, pero no dependen de tal o cual sujeto; se funden, se integran, se reacomodan en el marco de una corriente vital.

Puede ser interesante notar que, tal como se define aquí, ante la corriente vital se mantiene a salvo, no obstante, la razón; vida y razón deben articularse. Como lo presenta Virasoro, si puede apelarse a la intuición es porque "la intuición no es otra cosa que un proceso racional subconciente" ${ }^{31}$. Y subrayemos lo de racional, porque, salvando todas las imprecisiones teóricas que abundan en estos textos, es en esto en donde el autor dice separarse de Bersgon y su mirada negativa de la razón ${ }^{32}$. A diferencia de Bergson, dice Virasoro, la razón es parte del proceso de manifestación de la fuerza vital, en la medida en que es uno de los elementos que participa en el proceso de percepción de la "vida cósmica".

Aquí es donde nos encontramos con la cultura, ese gran universo de simbolización u objetivación de aquellas vibraciones. Y dentro de ese marco de expresiones culturales, el arte, en su forma plástica y literaria principalmente, ocupa un lugar preferencial. En las obras de arte es en donde con más claridad se manifiesta la vida. El artista parece ser el portador de las vibraciones, el traductor de aquella fuerza que rodea al hombre; su sensibilidad, siempre y cuando hablemos de un buen artista, un "artista creador", dice Virasoro, está preparada para captarla y volver a manifestarla. Por eso es la cultura

\footnotetext{
31 Inicial (2004), p. 582.

32 Eduardo Peñafort sostiene que esa defensa de la razón en los escritos de Virasoro, y la distancia de Bergson, se debe a la influencia de Ortega. Como sostiene Peñafort, Ortega es crítico de Bergson y es probable que las diferencias de Virasoro se asienten allí. Sin embargo, quizás esto puede explicarse también por lo que decíamos en la nota 26. Como anticipamos, las razones de una u otra recepción explícita pueden ser variadas. No obstante el rastreo de la época, su lenguaje, los debates y posiciones que se desplegaban nos permiten reconocer una íntima comunión en términos de sus propuestas filosóficas.
} 
el objeto por excelencia de la historia, allí se expresa la vida y allí parece necesario mirar para comprenderla.

Con lo cual, es comprensible que estemos también ante una definición del arte: más o menos cerca de la razón, dependiendo el autor que tomemos, siempre el arte se presenta en las antípodas de la utilidad. La belleza, dice González Lanuza, es inversamente proporcional a la utilidad ${ }^{33}$. Ese carácter creador del artista refleja su capacidad de elevarse por sobre lo percibido bajo la presión de nuestro intelecto. Ese artista logra percibir, dice el mismo Virasoro, "estados emocionales puros", 34 mostrando con ello una capacidad que habla del hombre en su conjunto. El arte aporta la imagen intuitiva, el poeta, el artista, nos muestra el espíritu, dice Ortelli, refiriéndose a Borges $^{35}$. En las antípodas del mundo natural, regido por leyes estrictas, el artista es la expresión misma de la libertad; no hay leyes, ni restricciones en su percepción y en su creación. Y es en esa capacidad de salirse de las restricciones que puede, también, hablarse aquí de "vanguardia": "esencialísimo factor de renovación y creación", imprescindibles en el proceso de autocreación del espíritu. Pero para ello debemos antes haber reconocido la centralidad y sentido de ese desarrollo ${ }^{36}$.

Dos cosas convienen revisar de esta invocación a una mirada intuitiva o creadora como fuente de verdad, para advertir de paso cómo ésta no supone el rechazo o el desplazamiento de la filosofía, sino lo contrario. Hay una armonía perfecta entre arte y filosofía, desde el momento en que la filosofía parece poder leer el lenguaje del arte y conceptualizarlo. El artista muestra, el filósofo reconoce. El arte es factor de renovación y creación, afirma Virasoro, porque las obras verdaderamente creadoras señalan "una etapa más en la evolución autocreadora del espíritu"37. Ahora bien, precisando, dice Virasoro en otro artículo publicado meses después: "siendo la filosofía fruto de selección de altiplanicie ideológica, sólo espíritus aristocratizados en las más duras disciplinas mentales logran alcanzar sus altitudes" ${ }^{38}$. Esos individuos son, precisamente,

\footnotetext{
33 Inicial (2004), p. 63.

${ }^{34}$ Inicial (2004), p. 241.

35 Inicial (2004), p. 90.

${ }^{36}$ Inicial (2004), p. 240.

${ }^{37}$ Inicial (2004), p.240.

38 Inicial (2004), p. 662.
} 
si seguimos de cerca ese texto, los que forman la "nueva generación". Si el acuerdo en este punto es generalizado y podría señalarse ahí el hilo medular de la revista y aquello que mencionábamos en torno a la mirada del tiempo que se ensaya, la opción que señala para la filosofía, diferenciándose más o menos explícitamente de otras expresiones próximas y contemporáneas, es bastante más ambigua. Al respecto, parece al menos importante reparar en esa idea de autocreación del espíritu.

A simple vista puede observarse la insistente presencia del relativismo y de la adaptación orteguiana de la teoría del físico alemán, que se articula con la lectura y valoración de Spengler, algo que se reconoce sin mucho esfuerzo en el lugar que se le da a la cultura, según dijimos arriba. Sin embargo, esto se tensiona con explicaciones que se asientan en valoraciones de orden universal, en el reclamo explícito de éstas y en la consecuente crítica a la teoría y lecturas de Spengler, "Filosofía de grandes masas y para grandes masas", 39 juzga Virasoro condenatoriamente. En términos generales, podemos decir que se invoca permanentemente una idea que excede las formas particulares de manifestación de la vida, o los puntos de vista infinitamente variados, y que el protagonismo otorgado a la cultura, que puede dialogar con Spengler, es paradojicamente el modo de fijar esas particularidades. El riesgo de Spengler podía, en ese marco, ser doble: permitir multiplicar la variedad, pero sobre todo habilitar una actitud historicista ante ésta, contra el convencimiento de la necesidad de intervenir para guiar la historia.

Quizás esa posición esté bien concentrada en la expresión de Etkin, que concluye su artículo sobre Spengler reconociendo y valorando la apelación spengleriana al género humano:

pero en cierto párrafo de su obra admite la existencia de valores eternos, al notar que hay algunos de una amplísima validez (...), con lo cual creemos que vuelve a la sana doctrina, porque no es posible desconocer que 'el hombre'

${ }^{39}$ Inicial (2004), p. 660. 
siempre es 'el hombre' y que existe y perdura algo idéntico e irreductiblemente humano ${ }^{40}$.

Asimismo, la idea de la "vida cósmica", tal como la repasamos antes, también se refiere a algo que parece exceder las particularidades. Y por último, ensayando un diagnóstico, quizás esa tentación en extremo relativista haya motivado la separación de algunos de los miembros originarios del grupo que llevaba adelante la publicación, tal como se señala la editorial del número 5 disidente ${ }^{41}$. Esa crítica pertinaz y disidente puede, sin embargo, encontrarse entre las razones de la posterior revisión de algunas afirmaciones, para abandonar el tono relativista o culturalista que acaso sea un signo singular de la editorial del número 4 . Con todo, parece inevitable no advertir esa tensión como signo de algo no resuelto en la revista. Si el relativismo permitía debatir la lógica moderna y racional de la historia, al tiempo que era una puerta abierta hacia las valoraciones regionales, el corte metafísico que se imprime a las definiciones teóricas hace suponer algo a lo que no se deseaba renunciar. Y probablemente, la apelación a Spengler sea el salvoconducto para aminorar la tensión, por cuanto, nos arriesgamos a decir, esa organización de la historia reconocía periodos históricos sin límites geográficos y tan extensos temporalmente que podían cargarse con el peso de lo universal. Con Spengler y, explícitamente, a pesar de él, desde el primer número, la revista señala que "en la historia hay una continuidad indiscutible del espíritu hacia su mayor intensidad de expresión" ${ }^{42}$. Recordaremos esto en cada juicio contundente que abra la revista, en particular, en cada referencia al arte.

Asimismo, ya a tono con buena parte de la filosofía de la época y en particular con el neokantismo, ${ }^{43}$ puede verse cómo la crítica al modelo de conocimiento de las ciencias naturales se apoya en la distinción libertad-necesidad y el dualismo que, si se niega en última instancia, les sirve también para establecer las diferencias, de manera tal que todo conocimiento en el plano de lo natural está atado a la necesidad. Es preciso pensar

\footnotetext{
40 Inicial (2004), p.467.

${ }^{41}$ Allí no sólo se invoca con insistencia la falta de unidad del grupo que llevaba adelante Inicial, sino que, dirigiéndose a los "jóvenes de América", se condena explícitamente la recurrencia a figuras inscriptas en la tradición europea, como Ortega y Spengler. Cfr. Inicial (2004), pp. 281-287.

42 Inicial (2004), p. 105.

${ }^{43}$ El texto que mencionamos de Peñafort avanza mucho en este sentido.
}

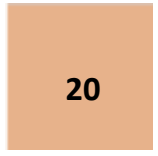


formas alternativas del desarrollo de lo humano, vinculadas con la libertad. $Y$ en ese marco, que es donde cobra relevancia o protagonismo el arte, el problema que se subraya al referirse a aquel esquema de conocimiento es el determinismo. No es posible pensar en una conceptualización próxima a las ciencias naturales que conciba la posibilidad de salirse de ese marco de constricciones que imponen las leyes de la naturaleza. Así, el razonamiento del oponente queda completamente reducido y limitado en relación con la historia del hombre que se ha redefinido completamente. 0 se está dentro del marco ajustado de la naturaleza, o se cruza la línea y el sujeto se mantiene ajeno a toda condición, creador de su mundo.

Estamos ante una nueva verdad, "la ilusión cientificista es definitivamente superada", ${ }^{44}$ dicen en aquella nota editorial del número 4. No la lógica cientificista, sino la ilusión, una lógica que ahora es señalada como falaz. Al engaño se le suma la inactualidad, o ésta es, probablemente, la causa de su desvalor. Esto se afirma a lo largo de toda la revista, aunque un artículo para destacar es el de Manuel Juan Cruz le dedica al libro de Alfredo Palacios, La universidad nueva, en el número 10. Destacamos ese texto porque nos permite mostrar cómo una argumentación compleja en términos teóricos, que parece cargada de nociones metafísicas, difícil de asir en el marco de lecturas más bien históricas, se articula con un motivo histórico-político. En este trabajo, el peso más contunde cae en relación con aquello que veíamos a partir de la editorial del número 9, la proximidad de Palacios a Ingenieros. Una proximidad que, si por el tema del artículo puede plantearse en términos ideológicos, no descuida en absoluto su costado conceptual. Y pareciera por momentos que eso es lo que está en juego: qué se entiende por filosofía y qué lugar ocupa este saber en el esquema universitario. A juicio de Cruz, en su concepción de la disciplina "Palacios no ha logrado aún superar la postura positivista" ${ }^{45}$. Planteado así, la nueva mentalidad que se promueve desde aquí es, por excelencia, filosófica y supone de manera obligada esa renovación, sugiriendo con ello que todo lo previo no posee este valor: "hemos opuesto al viejo tipo de cultura positivista y materialista, el nuevo de orientación humanista y filosófica", recordábamos que Guglielmini en la editorial del número $10^{46}$. Lo previo no sólo es

\footnotetext{
44 Inicial (2004), p. 225.

45 Inicial (2004), p. 745.

${ }^{46}$ Inicial (2004), p. 745.
} 
previo, pasado, sino que no es filosófico. De nuevo estamos ante el señalamiento de la ilusión, del error. Pero no sólo se contenta con señalar la caducidad de esas ideas, avanza más y las tilda también de "peligrosas". En relación con el diseño de la universidad y el lugar que ocupa ahí la filosofía, Cruz cuestiona el vínculo de ésta con la ciencia y señala "el peligro de una concepción semejante (...). Se pretende negar agrega- el peculiar carácter de la tarea filosófica en cuanto conocimiento de la actividad espiritual inaccesible a la pseudoconceptualidad científica" ${ }^{47}$. En aquel esquema, la filosofía ordenaba, correlacionaba, dice, los saberes científicos; en éste, en cambio, sus posibilidades se amplían tanto que resulta un orden no sólo diverso al de la ciencia, sino inaccesible para ella. La tarea de construir conceptos, los conceptos, podemos precisar, que leen y organizan lo que es, que pueden señalar en qué momento de la historia nos encontramos y cuáles son sus señas específicas, queda reservada para un solo saber.

Sobre esta nueva base, ahora filosófica, se van a discutir una serie de elementos de la vida política que cobraban sentido sólo en aquel marco ya superado y, por lo tanto, van a mostrar sus falencias: el constitucionalismo, el parlamentarismo, la democracia, el comunismo. La posibilidad de sostener el nuevo esquema conceptual se articula íntimamente con una mirada simplificadora y condenatoria del anterior en todo lo que se considera sus expresiones. No sólo hay allí una ilusión que parece caer por su propio peso, discutida en términos epistemológicos, podríamos decir, aunque en un sentido amplio, sino todo un modelo cultural, social y político que se condena porque al parecer se rige por aquella expresión falaz. La mirada crítica, que decreta el deceso, señala permanentemente un elemento que aparecía en aquella frase de Cruz: el binomio positivismo-materialismo. Esa diferencia del orden del pensar o del conocer, arrasaría, en el esquema que se propone aquí, con todo lo que se concibe derivado de esto, porque ya va quedando claro que aquí lo que priman son las ideas y las ideas rigen las épocas y sus diversas manifestaciones. La imposición de una nueva idea trae aparejado, inevitablemente, la mutación de los otros elementos históricos.

Precisamente, en aquella nota necrológica que le dirigen a Ingenieros abriendo el primer número de 1926, se afirma que para él la historia de la filosofía "era una serie

${ }^{47}$ Inicial (2004), p. 747. 
de sucesos contingentes, subordinados a los fenómenos políticos, y [que] jamás llegó a comprender su profundo significado como historia del espíritu humano en constante proceso de autoelaboración, irreductiblemente original en sus contenidos específicos" ${ }^{\prime 8}$. Se dice mucho, pero si distinguimos los elementos, advertimos que la idea de filosofía y del vínculo de la filosofía con las otras manifestaciones de su tiempo es completamente diferente en ambos esquemas. Por eso, ahora puede darse de baja el constitucionalismo, la democracia, el comunismo, entre otras cosas, sin más argumento que la crisis de aquellas ideas que regían su época. La inversión que se opera con respecto al vínculo de la filosofía con las manifestaciones humanas que le son contemporáneas en las diferentes dimensiones, se aplica retroactivamente, quitando incluso legitimidad a ciertas opciones políticas. Si la crisis ha sido decretada al nivel del "espíritu", entonces puede llevarse puesto todo. Porque en última instancia todo supone ese espíritu y su proceso de autoelaboración. La originalidad a la que se apela al final de aquella afirmación, puede plantearse tanto para referirse a la radicalidad de toda novedad, aunque más incluso para señalar su carácter iniciático, de fuerza que pone en movimiento y su absoluta autonomía respecto de otras dimensiones ${ }^{49}$.

Volviendo sobre esa generalización del oponente, se cuestiona el materialismo y el positivismo epistemológico porque, como dijimos, niegan o contradicen el elemento medular de la potencialidad de la filosofía: "una filosofía debe ser expresión de inquietudes y exigencias espirituales, no de exigencias prácticas, políticas o sociales" ${ }^{50}$. De manera simultánea se señala una y otra vez la casi indistinción entre esas ideas y las expresiones políticas materialistas. En particular, la conceptualización que atraviesa toda la revista, aunque con énfasis diferentes, es persistente en esa identificación. El cuestionamiento del positivismo está tan presente como el rechazo al materialismo en términos históricos y políticos. A juicio de sus autores, hay un problema en la lógica materialista que ha regido las últimas expresiones revolucionarias: "teología económica", "teología marxista", ${ }^{51}$ le llaman. Si ésta antepone los elementos

\footnotetext{
48 Inicial (2004), p. 638.

49 Es probable que estemos aquí ante el sentido más próximo a lo que los autores de la revista podrían considerar "vanguardia" en su expresión filosófica.

50 Inicial (2004), p. 661.

51 Inicial (2004), p. 73, 103 respectivamente.
} 
económicos como eje del desarrollo histórico, contra ella se afirmará la fuerza del espíritu, del amor, de las creencias.

La identificación positivismo-comunismo es insistente y está a la base de las posiciones estructurantes del discurso de la revista: "predicciones pseudocientíficas del socialismo" vs "eternas fuerzas inconcientes" que mueven la historia; 52 "el fracaso del ensueño comunista" que se identifica con la lógica racionalista, de las ideas abstractas, en contraposición a la "realidad palpitante y vital"; 53 "la ilusión cientificista es definitivamente superada", un relativismo que se hace real en el ocaso de las revoluciones, mostrando a Lenin como un "evangelista que equivocó las fuentes de su inspiración, bebiendo en el marxismo el ideal económico -ingenuo y precario como cualquier otro sistema social"; 54 "la errónea subordinación de lo teórico que ciertas escuelas establecen", desconociendo el peso de los elementos morales y de la fe, dice Cruz, citando a Croce y su condena del materialismo histórico y del socialismo. ${ }^{55}$ No obstante, cuando no se plantea valiéndose de esa identificación, la condena del marxismo sufre, sin embargo, la misma suerte: se constata su deceso, afirmando que se trata de un "palabrerío que fue fácilmente ahogado por la metralla a las puertas de París" 56 .

Hay, sin embargo, un pasaje en la revista -y subrayamos el hecho de que se trata de uno solo, en parte en función de las diversas lecturas de la revista y su inscripción en los debates político-intelectuales de la época- en que la mirada del comunismo podría sugerir alguna simpatía. Se trata del artículo titulado "La democracia en crisis", que aparece en el número 5 sin firma, y ya mencionamos rápidamente al referirnos a las editoriales. Allí, luego de la crítica a la democracia, se afirma que el comunismo, junto con el fascismo, son los dos polos entre los que vacila Europa, alejándose de la tradición democrática y liberal. Dos expresiones que, sin embargo, no son valoradas de la misma manera: "por una parte, la reacción y el fascismo la solicitan hacia el pretérito; por la

\footnotetext{
52 Inicial (2004), p. 132.

53 Inicial (2004), p. 205.

${ }^{54}$ Inicial (2004), p. 225.

55 Inicial (2004), p. 644.

${ }^{56}$ Inicial (2004), p. 181.
} 
otra, el comunismo procura sugerirle una visión de un porvenir mejor (...). Sólo la revolución rusa mantiene el prestigio de una esperanza, inquietante enigma inscripto en el umbral de occidente" ${ }^{57}$ Ese esfuerzo de mirar al porvenir, que posiciona al comunismo de cara a un futuro, parece diluirse cuando se revisan en detalle los términos de esta valoración. El comunismo ha sido situado en el umbral. No se trata de un efectivo avance hacia el porvenir, porque el futuro será redefinido en los términos nuevos que despliega, precisamente, la revista y que constitutivamente buscan quebrar con la lógica que rige aquella expresión política. Sólo reconociendo esa tensión, podemos articular esta afirmación, de septiembre de 1924, con aquella que hacían, también en el texto editorial, en marzo de ese año: "la impotencia constitutiva del comunismo"s8.

A lo largo de sus páginas, y en particular en las consideraciones histórico-políticas, el comunismo ocupa el principal lugar como objeto de la mirada crítica. Poco se dice sobre el constitucionalismo y la democracia, aunque menos aún del primero, que queda anulado en la crítica general al liberalismo sin más detalle. A la cuestión de la democracia se le destinan, sin embargo, algunos pasajes más, sobre todo en lo que hace a la mirada crítica de la democracia en Argentina.

Una referencia general se articula con la lectura de Ortega, en particular del libro $L a$ España invertebrada, una obra muy leída y debatida por esos años en Buenos Aires. Es una pluma no usual en la revista la que se ocupa de este comentario, la de Ariosto D. González, que firma en Montevideo, su ciudad de residencia. Más allá del acuerdo con las ideas de Ortega en aquel libro, lo que el autor sostiene como mirada general y de fondo de la democracia coincide, no sólo con el filósofo español, sino también con lo que se afirma en otros artículos de Inicial. La diferencia entre los intelectuales y el pueblo, el posicionamiento de los primeros como agentes concientes de la historia y la consecuente condena a todo régimen político que intente poner al pueblo, o siquiera invocarlo como fuente de legitimidad, le permite a González afirmar: "cuando alguien conmueve al pueblo, se trata, casi inevitablemente, de algún personaje menguado o subalterno" (267). La elite intelectual, formada por personalidades de relieve, según

57 Inicial (2004), p. 414.
58 Inicial (2004), p. 225.

Cuadernos del CILHA n $34-2021$

25

ISSN 1515-6125 | EISSN 1852-9615

CC BY-NC 2.5 AR

http://revistas.uncu.edu.ar/ojs/index.php/cilha/ 
dice, trabaja por conseguir una obra de alcance nacional, en que debe conducir al "rebaño anónimo". Pero quizás la crítica más rotunda, sobre todo como expresión de la revista, es aquella que ya mencionamos, con que se abre el número 6 . El texto ronda, como motivo, la crítica al krausismo, un modo tácito de posar la mirada sobre Yrigoyen, porque, a juicio de sus autores, fueron las ideas desplegadas por esta doctrina las que permitieron suponer algún valor para la democracia. El krausismo cae, sin embargo, luego de la guerra; parte del pasado, ha quedado caduco y caen con él todas las consecuencias que de allí se hayan obtenido, la democracia en primer término. La democracia es la expresión liberal y burguesa de la política, pero el liberalismo ha fracasado. Si el motivo general se concentra en las ideas, hacia el final la perspectiva se vuelve más histórica: Krause renovaba “el concepto de 'hombre providencial' que tanto necesitaban las jóvenes democracias (...). El 'repúblico' se convertía así en una especie de enviado de Dios, de tribuno ungido por el poder divino para lidiar por los derechos plebeyos. Este tipo de gobernante pseudoprovidencial lo hemos tenido en nuestro país, y hace muy poco tiempo" 59 .

Ortega pareciera ser el referente en lo que hace a la cuestión de la democracia. Casualmente el otro artículo que se destaca en relación con la mirada de la democracia es el que ya mencionamos de Juan Manuel Cruz, en donde se enfrenta a lo que considera la "política idealista" de Ortega y Gasset. Allí se debaten dos artículos de Ortega publicados en Revista de Occidente, "Parerga cosmopolitismo", de 1924, y "La reforma de la inteligencia", del 26, pero se trata precisamente de dos artículos en donde el español se alejaría de aquellas ideas de La España invertebrada, publicada unos pocos años antes. Lo que, a juicio de Cruz, deja mucho que desear ahora es su falta de compromiso político. Ortega se aleja con esos artículos de aquella mirada que ponía al intelectual en el centro de la escena política y esto justifica la condena por parte de su comentador. Al contrario, para Cruz, es preciso darle centralidad a la intelectualidad en la política y para ello es imprescindible que se piense la política de otra manera. Si, como hace Ortega, se reduce la política al terreno de las necesidades, es esperable que el intelectual no quiera o deba entrometerse allí, pero precisamente ese es el desafío, correr la política de lugar. "Opongamos -dice, invocando a Unamuno-

59 Inicial (2004), p. 411. 
a la 'política de realidades materiales' la de las idealidades de civilización, y en tal sentido dígase: (...) 'la historia de la civilización es política y sin lucha política no hay civilización posible'“60.

La misma idea está a la base de la lectura que se hace de la Reforma Universitaria y el modo cómo la revista reclame ser expresión del reformismo. La Reforma va de la mano de la nueva generación y las tareas que se le han asignado, mediante el descubrimiento del vínculo entre la capacidad de percibir el desarrollo del espíritu, la intelectualidad y la política. Así, la Reforma Universitaria adquiere de ahí su función: "la reforma integral de la inteligencia y de la cultura" ${ }^{\prime 1}$. La Reforma es condición de posibilidad de toda la novedad epocal que se anuncia. Y nuevamente estamos ante el mismo problema de la tensión que se genera entre el anuncio de lo nuevo o por venir y su ausencia actual. Una tensión que es la base sobre la que se otorga la máxima legitimidad al protagonismo de la juventud: la realización de la novedad supone agentes que ofician de guías y que no reconocen maestros porque el tiempo es nuevo. Así, la Reforma no ha sido hecha aún. En su lugar hay una crisis que muestra todavía el fin de lo viejo y anuncia ya la llegada de lo nuevo. Lo inédito necesita, para su despliegue, del trabajo conciente de la juventud y en ese marco la universidad es presentada como el escenario por excelencia de esa potencialidad. Ésta supone una reforma pedagógica que debe poner en el centro la formación de orientación humanista y filosófica que señalaba Guglielmini. Sólo de este modo se arribaría a la tan deseada "conquista espiritual".

Por último, esas nociones se articulan con el modo cómo se piensa América Latina y su lugar en la historia. Si bien la revista habría sido invitada a las reuniones preparatorias de la fundación de la Unión Latino Americana a comienzos de 1925 y alguno de sus redactores habría participado de ellas, según se cuenta, la editorial del número 8 se ufana de marcar algunas de sus diferencias con la línea predominante de aquella iniciativa ${ }^{62}$. Como hemos citado arriba: "la verdadera batalla se libra en el terreno

${ }^{60}$ Inicial (2004), p. 642.

${ }^{61}$ Inicial (2004), p. 695.

${ }^{62}$ Sobre este punto la información, sin embargo, no es clara. Alexandra Pita consigna la participación en esas reuniones de Brandán Caraffa como representante de Inicial. No obstante la fecha de esa reunión sería marzo de 1925 y sabemos que para entonces este intelectual se había separado del grupo que hacía Inicial (Pita, 2009, pp. 110-112) Por su parte, la revista afirma en la editorial del número 8: "invitada a colaborar a la 
cultural", ${ }^{63}$ decían los editores de nuestra revista. Se avanza aquí sobre esa idea, intentando dejar en claro diferencias de fondo que no habrían sido recuperadas en las definiciones de la Unión. Insistiendo sobre la idea de que lo "iberoamericano" se refiere a una dimensión cultural y no política, se condena como utópico cualquier intento de unión política entre las naciones del continente. Se señala en esa expresión la convicción de oponerse "a la orientación que pretende reducir todos los problemas posibles a una ecuación política, económica o social". Se reconoce allí la tendencia a "evadir toda suerte de inquietud espiritual (...), un error de perspectiva que reconoce tal vez como una de sus fuentes el añejo materialismo histórico y la ideología marxista, último evangelio de una juventud sin profundidad filosófica y sin conocimiento crítico" ${ }^{64}$.

Esta valoración de América Latina desde esa perspectiva cultural o espiritual nos lleva nuevamente a aquello que mencionábamos en relación con el relativismo y sus límites. Frente a la mentalidad norteamericana, se celebra "la tradición latina con caracteres privativos, que encarnan los países de la América íbera" ${ }^{65}$. Se resalta un carácter exclusivo, se distingue a América Latina de algún curso histórico más amplio, aunque no para refugiarse en el valor acotado de esta cultura, sino para tomarlo de base para una nueva universalización, a la que todavía gusta inscribir dentro de Occidente. América pareciera servir para interrumpir la lógica de la historia, para volver a pensarla, a darle un curso nuevo desde cero y con nueva dirección y ejes. Esta América pareciera un primer mojón que señala la posibilidad de torcer la mirada hacia lo espiritual. Y en esa mirada, junto con cierta parte de Europa, América del Norte es condenable por reconocerse allí una de las expresiones más patentes de lo que muere. Lo que muere es más que una cultura o un momento de la cultura occidental, es una lógica de comprensión de lo que es, un modo de representar el mundo, es una manera de pensar la historia. De ese modo, "la América del porvenir", como le llaman, no es una cultura

organización de un próximo Congreso de la Juventud Iberoamericana nuestra revista ha asumido desde el primer momento una actitud más bien polémica y crítica de ciertos puntos concretos" (Inicial, 2004, 563).

${ }^{63}$ Inicial (2004), p. 567.

${ }^{64}$ Inicial (2004), p. 564.

${ }^{65}$ Inicial (2004), p. 567. 
más que convive con otras, y no sólo es el modelo cultural por excelencia, es condición y modelación del porvenir, es transformación de las posibilidades de hablar de porvenir.

En esto se basa, en buena medida, la lectura crítica de Spengler. Porque si, junto con los otros autores valorados en la revista, Spengler ha permitido revisar la lógica del progreso como único modelo del desarrollo de la historia, reaparece con el paso del tiempo y en boca de los autores más representativos de la revista cierta reticencia que se deriva de su carácter de europeo. En esa línea, se impone la novedad de que en América Latina hay verdaderamente algo novedoso y disruptivo, "una violenta elevación del tono vital", ${ }^{66}$ dice Virasoro. $Y$ atender a esto es la tarea principal y más ardua de las nuevas generaciones: "la violenta reencauzación de su sensibilidad superior dentro del núcleo más importante de su tradición racial” ${ }^{37}$. Esa generación puede ser, efectivamente, "nueva" porque está en América. Como expresa un artículo sin firma en el número 1: en "la tan calumniada South America" están en potencia las posibilidades para el futuro del mundo ${ }^{68}$.

Por su parte, el entusiasmo en torno a esa Hispanoamérica se combina por momentos con algunas expresiones de corte nacionalista, como las que desplegaba Bandan Caraffa en el primer número vinculando la valoración nacional con la exaltación de Italia, para incluso proclamar el llamado a ser "la Sicilia del siglo XX", por el perfil agrícola de la actividad que en el país se desarrolla y lo que se consideran pueden ser sus consecuencias para el desarrollo cultural ${ }^{69}$. Si la referencia a Italia es una constante, ésta se articula con la valoración de la cultura española que amplía la mirada a las naciones del sur del continente: "hijas de una misma madre"70. "Comunidad de razas y

\footnotetext{
${ }^{66}$ Inicial (2004), p. 587.

${ }^{67}$ Inicial (2004), p. 663.

${ }^{68}$ Inicial (2004), p. 97.

69 Inicial (2004), p. 60.

${ }^{70}$ Inicial (2004), p. 182. La proximidad con la cultura española, de donde reciben el caudal más amplio en términos de orientación intelectual y los sucesos ocurridos en ese país con el ascenso de Primo de Rivera son dos elementos que se articulan en la permanente y cada vez más marcada valoración del vínculo. Un claro ejemplo de esa combinación es el breve texto sin firma que, en repudio al destierro de Unamuno, se publica en el número 4, el primer número de 1924. Cfr. 243-245. Sobre la mirada latinoamericana de la dictadura española puede consultarse: Melgar Bao, R. (2015). Sobre el vínculo de la revista con la cultura italiana como modelo, Fernando Rodríguez nos recuerda los muchos y variados elementos que permiten mostrarlo.
}

Cuadernos del CILHA n $34-2021$ 
hasta de tradición; esa peculiar atmósfera psicológica que Renán señala como el factor básico de la nacionalidad misma"71 se encuentra en esta Hispanoamérica y es precisamente el origen de su fuerza para enfrentarse al enemigo también común.

\section{Algunas consideraciones finales}

"Sabemos que existe una juventud que se ha puesto al ritmo vertiginoso de la hora histórica, y esa juventud tiene muchas cosas para decir", ${ }^{72}$ se afirmaba al comienzo de la editorial del primer número de Inicial, para luego adjudicarse el rol de vocera de eso que había para decir. Lo que había para decir era, precisa y redundantemente, que había algo nuevo para decir. Lo que la revista buscaba era instalar la idea de la novedad, una novedad que, al mismo tiempo, se presentaba como algo de lo que sólo el discurso que ella encarnaba era parte. Si allí mismo había de entrada una movida filosófica de gran importancia, con el paso de los meses se avanzaría en modelar y precisar su sentido.

Hemos recorrido algunas de esas certezas, las más próximas a lo que consideramos la definición filosófica que atraviesa la revista. Inicial construye una idea de novedad para sí misma, pudiendo decir que ella es intérprete de la inauguración de una nueva era. Se trata de una nueva época habilitada conceptualmente y en la que la filosofía, como saber autónomo y con ciertas precisiones bien definidas, ocuparía un rol protagónico. La definición de esta novedad supone pararse ya en nuevas bases. Si estas van apareciendo de la mano de algunos notables autores europeos, que hemos ido mencionando, lo cierto es que su valoración como inicio de algo diferente puede aparecer porque va acompañado de un arduo trabajo, tanto teórico como retórico, del que se ocupa la revista. En ese sentido, la novedad debe ser leída como una construcción en esos dos sentidos, retórica y conceptual.

En esa línea, aunque no lo hemos tematizado en las páginas anteriores, resulta sugerente el hecho de que no sea fácil trazar una mirada reticular de esta publicación en lo que respecta al escenario filosófico. Si muchos trabajos recientes sobre el estudio

\footnotetext{
71 Inicial (2004), p. 162.

72 Inicial (2004), p. 47.
}

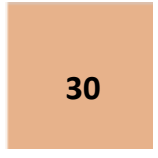


de revistas sugieren la productividad de una mirada que atienda a los vínculos que se van trazando con el escenario intelectual en el que se desarrollan las publicaciones, parece también interesante notar qué dice de una revista el hecho de que esos cruces sean más bien ocasionales. En los números de Inicial es frecuente la referencia al mundo cultural, comentando puestas teatrales, salones de pintura, reproduciendo algunas poesías, o ejerciendo la crítica literaria. En todos los casos se patentizan los vínculos estrechos con representantes de la vanguardia literaria, ${ }^{73} \mathrm{sin}$ embargo no pasa lo mismo con el escenario filosófico. Más allá de algunas referencias más detenidas a unos pocos intelectuales consagrados del momento, aunque siempre recordando que son expresión de una generación anterior, no encontramos vínculos manifiestos al interior de sus páginas. Pocos de sus números incluyen referencia a bibliografía o reseñas de libros del momento. En el caso particular de las referencias a revistas, que encontramos en los números 3, 4, 6 y 11, en su mayoría son muy breves y, atendiendo a las publicaciones del ambiente, se cuentan la "Revista de Indias", publicación del Ateneo Universitario, Valoraciones y la Revista de Filosofía ${ }^{74}$. En el plano internacional encontramos la referencia a la Revista de Occidente. Ninguna de las tres revistas rioplatenses mencionadas recibe una valoración positiva: sobre la "Revista de Indias", luego de una presentación elogiosa, se afirma que "vale más por lo que puede ser -y tenemos fe en su porvenir- que por lo este primer número presenta en sí"75. El número 4 despacha en cinco renglones la Revista de Filosofía, arguyendo que Ingenieros usaría sus páginas para publicar las "conocidas versiones de sus clases de la Facultad de Letras ya publicadas"76. Sobre Valoraciones, finalmente, se manifiesta en ese número 4, elogiando el homenaje a Ripa Alberdi y un artículo de Amaya sobre Rickert, y en el número 6 se incluye un comentario en el que, tras celebrar la aparición de un artículo de Carlos Astrada en la revista platense y llamarla "revista amiga", le endilga "el tono académico que adopta a las veces la revista (que) le sienta mal y traiciona el simpático

\footnotetext{
${ }^{73}$ Como señala Fernando Rodríguez, Borges, Córdoba Iturburu, González Tuñón, entre otros están presentes en sus páginas. Del mismo modo, hay rastros del vínculo con otras publicaciones e intelectuales cuando se relatan algunos eventos como el homenaje a Rojas, organizado en diciembre de 1923, o "la primera comida de Inicial"-que es la única consignada (Inicial (2004), p. 257)-, de los que participa una importante variedad de intelectuales.

${ }^{74}$ No hemos podido recuperar información de archivo sobre la Revista de Indias.

75 Inicial (2004), p. 215.

76 Inicial (2004), p. 270.
} 
esfuerzo inicial que le diera luz". En cierta tensión con esto, se advierte que, entre las escasas propagandas de revistas del ambiente que incluyen sus páginas en el formato de simples recuadros con datos básicos, las más recurrentes sean precisamente las dedicadas a la filosofía y no a la literatura. Entre ellas, se destacan por la cantidad de propagandas, nuevamente, Valoraciones y la Revista de filosofía.

Como vimos en este recorrido, Inicial se interesa por la filosofía. Probablemente sea por eso que tantos historiadores e historiadoras reconocen en ella la marca de una nueva expresión del pensamiento argentino de los 20. Pero Inicial necesita, para imponerse e imponer su idea de filosofía, anteponer la idea de lo nuevo y al hacerlo parece buscar destacarse en su propio escenario sin valerse de alguna inscripción que la lleve a consagrarse por la comunión de ideas con espacios más reconocidos. Y lo mismo ocurre con sus editores, no se trata de intelectuales que encontremos con frecuencia en otras revistas de la época o cuya inserción en otros espacios del ámbito cultural sea utilizado como herramienta de sentido en la revista. Esto último probablemente tiene que ver con el hecho de que se trataba de personalidades bastante jóvenes al momento de publicar la revista, dato, que más que cerrar esta lectura, invita a avanzar en futuras exploraciones en torno a los derroteros posteriores a esta experiencia y al modo en que estos desarrollos dialogan efectivamente con otras expresiones de la época.

Efectivamente, Inicial presenta una posición filosófica que rompe con lo anterior. No hemos explorado aquí esos cruces, porque preferimos concentrarnos en lo que creemos era aún una lectura pendiente. En ese sentido, hemos visto cómo el esfuerzo se concentraba en elaborar esa ruptura, pensarla, definirla, conducirla. Analizamos aquí algunos de los ejes de esa definición, centrándonos en la filosofía, y advertimos que esa posición que se despliega en las páginas de Inicial va de la mano de una mirada crítica no sólo de la filosofía de su tiempo, ese tiempo que se considera ya pasado, sino del contexto en que ésta se inscribe. La crítica en términos de ideas es una crítica a todo lo que se vincula con éstas: un error de concepción que no se asienta sino en una diversa creencia o manera de mirar al hombre y al mundo, que, según la lógica de relaciones entre los elementos históricos, afecta al hombre y su mundo, y con ello a sus múltiples objetivaciones: saberes, política, economía, sociedad.

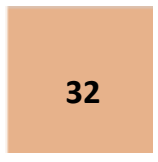


Sin pretender hallar allí una posición ideológica de base que sostendría y explicaría en última instancia las pretensiones de la revista, el largo recorrido que nos propusimos buscó ensayar una exploración conceptual que pusiera de manifiesto cómo la revista fue elaborando las condiciones teóricas que hicieran pensable y necesario, incluso condición del pensamiento, una novedad que la volviera a ella misma protagonista de ese tiempo que decía inaugurar. Cómo fue posible para Inicial reconocer y condensar lo que la juventud tenía para decir, cuáles fueron las condiciones de esa posibilidad. Si, como dijimos al comienzo, esta publicación se caracteriza por su posicionamiento antipositivista, podía todavía explorarse en detalle los supuestos, el sentido y sus implicancias de esa negación, porque lo que vemos en Inicial es que construye una lógica que saca del juego a su oponente. Otros autores de la época pudieron cuestionar el positivismo pero no usaron los mismos recursos ${ }^{77}$.

Lo que se observa, entonces, desnaturalizando la oposición, reconociéndola como una construcción de los mismos autores y actores, es que esa estructura está atravesada por la voluntad de disputa. En ese sentido, Inicial parece estar signada por una preocupación que además de estética y filosófica, es política. Si la expresión "antipositivismo" ya, desde un comienzo, nos sitúa ante el intento de marcar una diferencia y oposición, no parece incorrecto leer esa fórmula como signo de una preocupación que, además de estética y filosófica, posee ribetes políticos. Pero incluso aún, si las diferencias se despliegan con facilidad en el ámbito cultural e intelectual, se hacen patentes también, a menudo, en sus derivas histórico-políticas. El enfrentamiento que lleva como la bandera de la novedad se despliega tanto el plano conceptual como histórico-político. Inicial crea y sostiene la tensión. Reconociendo eso podemos revisar algunas identificaciones o simplificaciones de la historia que contamos de los 20 en la Argentina, de esa historia que solemos reconocer plagada de reformismo y antiimperialismo. Del mismo modo, y si es que vale, para la historia de la filosofía, podemos recordar que sus definiciones y redefiniciones suponen algunos motivos $y$

\footnotetext{
77 Dotti reconoce expresiones de "transición", que de alguna manera sitúa como anticipos a las posiciones "de ruptura". Más allá de que no acordemos en la categoría utilizada porque, igual que señalamos en relación con "vanguardia", encontramos aquí un supuesto historiográfico muy cargada, es claro que en el contexto confluyen muchas y variadas posiciones filosóficas.
}

Cuadernos del CILHA n 34 - 2021 
"Lo que piensa la juventud..." Inicial y su intervención conceptual

vínculos que exceden el acotado escenario que este saber pretende construir en torno suyo.

\section{Referencias}

Bustelo, N. (2010). Hermanas abrazadas, filosofía y literatura en la reacción antipositivista. En A. Mailhe (comp.), Pensar al otro/pensar la nación. Intelectuales y cultura popular en Argentina y América Latina, vol. II. Al margen.

Dotti, J. (1992). La letra gótica. Recepción de Kant en la Argentina, desde el romanticismo hasta el treinta. Facultad de Filosofía y Letras, UBA.

Inicial. Revista de la nueva generación (2004). Universidad Nacional de Quilmes

Melgar Bao, R. (octubre-diciembre, 2015). Legado y espejo de la Reforma Universitaria latinoamericana en España (1919-1926), Pacarinas del sur, 6 (25), 6-25. http://www.pacarinadelsur.com/56-dossiers/dossier17/1206-legado-y-espejo-de-la-reforma-universitaria-latinoamericana-en-espana-1919-1926

Peñafort, E. (1987). El pensamiento filosófico del Dr. Miguel Ángel Virasoro. Cuyo, 4, 33-69https://bdigital.uncu.edu.ar/objetos_digitales/4266/04-vol-04-penafort.pdf

Pita, A. (2009). La Unión Latino Americana y el Boletín Renovación. El Colegio de México.

Pró, D. (1965). Periodización del pensamiento argentino. Cuyo, 1, 7-42. https://bdigital.uncu.edu.ar/app/navegador/?idobjeto $=4138$

Rodríguez, F. D. (2004). Estudio preliminar. En Inicial. Revista de la nueva generación (1923-1927) (págs. 145). Universidad Nacional de Quilmes.

Tarcus, H. (2020). Las revistas culturales latinoamericanas. Tren en movimiento.

Terán, O. (2008). Historia de las ideas argentinas. Siglo XXI.

Velarde Cañazares, M. (2013). La joven vanguardia filosófica argentina de la década del 20. Cuyo, 30, 61-87. https://bdigital.uncu.edu.ar/6539 